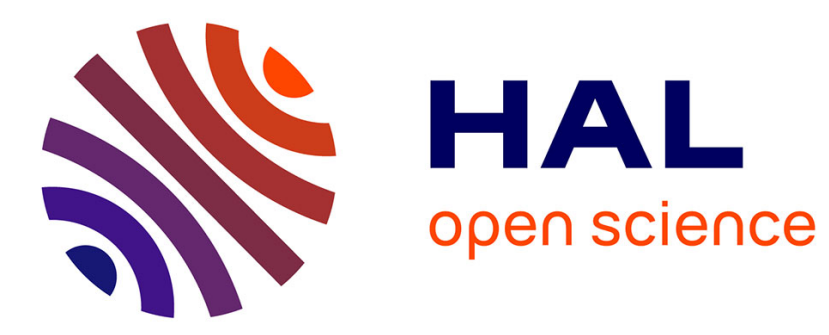

\title{
Epigenetics and Sjögren's Syndrome
}

Christelle Le Dantec, Marie-Michèle Varin, Wesley H Brooks, Jacques-Olivier

Pers, Pierre Youinou, Yves Renaudineau

\section{To cite this version:}

Christelle Le Dantec, Marie-Michèle Varin, Wesley H Brooks, Jacques-Olivier Pers, Pierre Youinou, et al.. Epigenetics and Sjögren's Syndrome. Current Pharmaceutical Biotechnology, 2012, 13 (10), pp.2046-53. 10.2174/138920112802273326 . hal-00771074

\section{HAL Id: hal-00771074 \\ https://hal.univ-brest.fr/hal-00771074}

Submitted on 2 Dec 2017

HAL is a multi-disciplinary open access archive for the deposit and dissemination of scientific research documents, whether they are published or not. The documents may come from teaching and research institutions in France or abroad, or from public or private research centers.
L'archive ouverte pluridisciplinaire $\mathbf{H A L}$, est destinée au dépôt et à la diffusion de documents scientifiques de niveau recherche, publiés ou non, émanant des établissements d'enseignement et de recherche français ou étrangers, des laboratoires publics ou privés. 


\title{
Epigenetics and Sjögren's Syndrome
}

\author{
Christelle Le Dantec ${ }^{1}$, Marie-Michèle Varin ${ }^{1}$, Wesley H Brooks ${ }^{3}$, Jacques-Olivier Pers ${ }^{1,2}$, \\ Pierre Youinou ${ }^{1,2}$ and Yves Renaudineau ${ }^{1,2, *}$
}

\author{
${ }^{I}$ EA2216 Immunology and Pathology, IFR 148 ScInBioS, Université de Brest, Brest; Université Européenne de \\ Bretagne, France; ${ }^{2}$ Laboratory of Immunology, Pôle biologie, CHU Brest, Hôpital Morvan, Brest, France; \\ ${ }^{3}$ Experimental HTS, Drug Discovery; H. Lee Moffitt Cancer Center \& Research Institute; Tampa, Florida, USA
}

\begin{abstract}
There is growing evidence that epigenetics, the study of heritable changes in gene expression that do not involve mutations in the DNA itself, may play an essential role in autoimmune diseases (AID). In Sjögren's syndrome (SS), a chronic AID characterized by an epithelis of the exocrine glands, epigenetic studies have focused on three mechanisms: DNA methylation and its consequences including human endogenous retrovirus (HERV) expression; microRNA expression; and protein post-translational modifications associated with autoantibody production. Although in its infancy, comprehension of the epigenetic (dys)regulation in SS may help us to understand: why SS affects predominantly middle-aged women; why genetically predisposed individuals develop SS but not others; why flare-ups occur; why treatment responses differ between patients; and why some patients develop lymphoma. From these studies will arise a better comprehension of the pathophysiology of SS as well as development of new diagnostic and prognostic biomarkers, and novel therapeutics for prevention and perhaps early intervention.
\end{abstract}

Keywords: Sjögren's syndrome, epigenetics, DNA methylation, microRNAs, post-translational modifications, human endogenous retrovirus.

\section{INTRODUCTION}

Sjögren's syndrome (SS) is a chronic autoimmune disease affecting exocrine glands, mainly the salivary and lacrimal glands, leading to its designation as autoimmune exocrinopathy or autoimmune epithelitis [1]. Systemic features may be present, and patients with SS have a 20-40 fold increased risk of developing lymphoma [2-4], mostly salivary gland lymphoma. In the different SS manifestations, the epithelium is affected and injury is associated with dense lymphocytic infiltrates composed of activated T and B cells [5]. Epithelial cells play a central role in the disease through the recruitment and activation of lymphocytes, and the release of apoptotic blebs containing autoantigens $(52 \mathrm{kDa}$ and $60 \mathrm{kDa}$ $\mathrm{Ro} / \mathrm{SSA}, \mathrm{La} / \mathrm{SSB}, \mathrm{Sm})[6]$.

The etiology of SS is multifactorial and arises from an interplay of genetic predispositions, in particular HLA-DR allele subtypes, and specific gene polymorphisms including the ancestral haplotype 8.1, IL-10, SSA1, FCGR3B, CCL3L1, IRF5 and STAT4 [7-9]; immunological deregulation such as autoantibody $(\mathrm{Ab})$ production; and environmental factors like UV light, nutrition, exposure to infectious agents, and drugs [10]. Interestingly, exposure to environmental factors, geographical particularities, radiation exposure, and sex have been advanced recently to explain the broad prevalence, $0.1 \%$ to $4.8 \%$, reported in SS [1].

Initially, epigenetics was introduced to describe how environmental factors may influence a cell heritably or reversibly

*Address correspondence to this author at the Laboratory of Immunology, Brest University Medical School Hospital, BP824, F-29609, Brest, France; Tel: 33-298-22-33-84; Fax: 33-298-22-38-47;

E-mail: yves.renaudineau@univ-brest.fr without affecting the nucleotide sequence of the DNA. Now, a more precise definition of epigenetics relates it to specific cellular processes including the control of transcription by DNA methylation and histone modifications, the control of transcripts by microRNAs (miRNA), and the influence on cellular regulatory processes by protein post-translational modifications (PTM). As a consequence, epigenetic processes control cellular differentiation and development, cellular life span, progression of carcinogenesis, and last but not least, the immune system.

\section{DNA METHYLATION AND CHROMATIN REMO- DELLING}

\subsection{DNA Methylation and Histone Modifications}

The density of chromatin varies along each chromosome with dense regions referred to as heterochromatin and less dense regions referred to as euchromatin. Heterochromatin participates in the inactivation of the genes, in the compaction of centromeres and telomeres, and in the silencing of transposons, such as human endogenous retroviruses (HERV) that are present in the "junk DNA". Regulatory gene sequences present in the heterochromatin are characterized by increased DNA methylation of cytosines in the $\mathrm{CpG}$ motifs, histone deacetylation, and recruitment of non-histone DNA-binding proteins, like the heterochromatin protein 1 that blocks transcription factor access to promoters. In contrast, euchromatin is found in areas of transcriptionally active genes and shows decreased DNA methylation, and increased histones modifications such as acetylation.

Throughout the genome, methylated sites are distributed on about $70 \%$ of CpGs. The remaining demethylated motifs 
are concentrated in short repeated $\mathrm{CpG}$ sequence domains, called $\mathrm{CpG}$ islands, that control gene expression when associated with gene regulatory regions. In cancer cells, DNA methylation has been shown to contribute to gene silencing of tumor suppressor genes, and to DNA mutations and chromosomal instability when DNA methylation concerns $\mathrm{CpG}$ islands outside of regulatory areas. DNA methylation occurs by covalent addition of a methyl group from the methyl donor S-adenosyl-L-methionine (SAM) to the $5^{\prime}$ carbon of the cytosine ring in $\mathrm{CpG}$ pairs. At least five DNA methyltransferases have been characterized (DNMT1, DNMT3a, DNMT3b, DNMT3L and DNMT2). DNMT1 preferentially methylates hemi-methylated substrates, such as appear during cell division, and thereby DNMT1 contributes to the maintenance of DNA methylation patterns. DNMT3a and DNMT3b methylate unmethylated DNA and thus contribute to de novo methylation. DNMT2 displays only weak DNA methyl transferase activity. Its main function is to methylate aspartyl-tRNA. DNMT3L binds DNMT3a and DNMT3b to regulate their functions. DNA methylation causes transcriptional repression of associated genes directly by reducing the affinity between transcription factors and their target DNA, or indirectly via methyl-CpGbinding proteins (MBD), a group that includes MECP2, MBD1-MBD4 and Kaiso. The main function of MBD is to recruit proteins that do not bind directly to DNA, such as the histone deacetylases (HDACs) and HP1. Genetics and epigenetics are linked since it has been demonstrated that polymorphisms in the X-linked MECP2 gene confer a risk for development of systemic lupus erythematosus (SLE) [12]. However, association with SS is currently unknown.

Histones are small well-conserved proteins associated with DNA in a fundamental unit called the nucleosome that controls chromatin condensation and decondensation. Noncondensed nucleosomes resemble "beads on a string", and each bead or nucleosome consists of two copies of the four histones (H2A, H2B, H3 and H4) surrounded by 146 bp of DNA coiling twice around the histone core. The number of nucleosomes per cell has been estimated at around 10 million, and they are separated by $10-80$ bp of linker DNA. In condensed DNA, the linker histone $\mathrm{H} 1$ binds to the linker DNA between nucleosomes to facilitate compaction. The histone amino terminal tails protruding from the nuclesomes are subject to many PTM including acetylation, methylation, ubiquitination, phosphorylation, sumoylation, deimination/citrullinisation, ADP ribosylation, and proline isomerization [13]. Histone PTM are recognized by specific proteins in order to control DNA folding via DNA-histone, histonehistone and nucleosome-nucleosome interactions. The most intensively studied modifications are acetylation and methylation. Indeed, the activity of histone acetyl transferases (HATs) is counterbalanced by HDACs that remove the acetyl groups. HDACs are divided into four classes: class I consists of HDAC 1-3 and 8 (nuclear localization), class II consists of HDAC 4-7 and 9-10 (cytoplasmic and nuclear localization), class III consists of sirtuins (SIRT 1-7) and class IV consists of HDAC 11 which exhibits features of classes I-II. Similarly, the impact of arginine or lysine methylation by histone methyl transferases (HMTs) is reversed by demethylating enzymes. It should be kept in mind that one histone can carry different modifications at any given time and that histone modifications are dynamic and can change rapidly in response to stimuli. In addition, PTM are not restricted to histones since, for example, HDAC2 can modify up to 200 non-histone targets including the U1 small nuclear (sn)-ribonucleoprotein (RNP) and the small cytoplasmic (sc)-RNP proteins $60 \mathrm{kDa}$ Ro/SSA and La/SSB.

\subsection{Twin Studies}

Studies involving monozygotic twins (MT) that are genetically identical constitute the ideal model to study epigenetic modifications [14]. Fraga et al. have demonstrated that DNA methylation patterns and histone acetylation profiles diverge in the peripheral blood between younger and older healthy MT [15]. Furthermore, it was also noted that MT with the greatest differences were those who have spent less of their lives together, thus providing evidence that changes may be related to differences in environmental exposures and/or diet. Using peripheral blood mononuclear cells (PBMC) from pairs of siblings discordant for SLE, rheumatoid arthritis (RA) and dermatomyositis (DM), the same group has reported that only MT discordant for SLE, but not for RA or DM, exhibited global loss in their DNA methylation status when 807 promoters were analyzed [16], and this was associated with a reduction in DNMT1 and DNMT3b transcripts. Methyl cytosine modifications among 5 SLE twins and their corresponding healthy MT were scrutinized in more detail revealing a common set of 49 demethylated genes. Among the differentially methylated genes, some of them are involved in the immune response including IL-10, CD9, CD82, PECAM, the interferon gamma receptor 2 (IFNRG2), and the colony stimulating factor 3 receptor (CSFR3).

\subsection{Epigenetics in Aging}

The combined influence of aging and environmental factors in the epigenome may provide an explanation for agerelated AID development. Indeed, when analysing DNA methylation status, a reduction with age is observed in the elderly and it appears to be proportional to the life expectancy [17]. Similarly, chromatin reorganization is observed in senescent cells in association with histone modifications [18]. However, studies of histone modifications in the elderly have concentrated mostly on the association between cellular life span and the NAD+ dependent HDAC class III sirtuin family. Indeed, manipulation of sirtuin activity influences cellular longevity positively when over-expressed and negatively when under-expressed [19]. Interestingly, young SIRT1 -/- mice develop an SLE-like disease with antinuclear Abs (ANA) and glomerulonephritis. When they survive up to two years of age, a diabetes insipidus appears [20]. Sirtuin expression is controlled by environmental factors. In fact, smoking is associated with SIRT1-2 downregulation and pro-inflammatory cytokine production, an effect prevented with the utilization of the SIRT1 activator resveratrol isolated from red wine. The beneficial effects of sirtuin inhibitors and HDAC class I-II inhibitors have also been demonstrated in different AID mouse models showing that the effect was related to reduction of cytokine production while autoAb synthesis remained unaffected [21-23]. The relation between life span and HDAC class I-II is still being debated. 


\section{CHROMATIN MODIFICATIONS IN SS}

\subsection{DNA Methylation in SS}

Hydralazine and procainamide, drugs known to induce SS with immunological features of an SLE like disease [2425], possess the capacity to remove the methyl group from cytosines present in $\mathrm{CpG}$ islands and, therefore, are referred to as demethylating agents. Both drugs, when given orally to mice for several weeks, are responsible for the development of an SLE-like disease with ANA [26]. Variations were observed depending on the animal strain, age, and sex and the effect disappeared after discontinuation of the drug. Richardson's group has demonstrated that hypomethylated $\mathrm{CD}^{+} \mathrm{T}$ cells became autoreactive. Indeed, passive transfer of $\mathrm{CD}^{+} \mathrm{T}$ cells pre-treated with either of two distinct DNA methyltransferase inhibitors, 5-azacytidine or procainamide, into mice induced anti-dsDNA Ab production with the characteristics of a severe immune complex glomerulonephritis [27]. The influence of DNMT inhibitors was also addressed in B cells using bone marrow B cells pretreated with hydralazine and re-injected by passive transfer into syngenic mice leading to the detection of anti-nucleosome Abs in the recipients [28]. Similar to what was observed in SLE, scleroderma and DM [29], Yin et al. have recently reported that DNA methylation is impaired in CD4+ T cells isolated from patients with SS [30]. As a consequence, several methylation sensitive autoreactive related genes are overexpressed. Among these genes, the promoter region flanking the CD70 gene, a B cell co-stimulatory molecule, is demethylated and CD70 is over-expressed in SS CD4+ T cells.

Different $\mathrm{T}$ cell and B cell subpopulations are characterized by abnormal DNA methylation patterns. First, the senescent CD4+ CD28- CD70+ Kir+ subpopulation, which is increased in RA and spondyloarthritis [31], second the defective pre-Treg CD4+ CD25- subpopulation that overexpress FoxP3 but lack regulatory functions [32], and third the $\mathrm{CD}^{+}$ B cell [33]. In SS, whereas the CD4+ CD28- subpopulation is not altered, FoxP3 $+\mathrm{T}$ cells and CD5+ B cells are overexpressed in the blood and salivary glands from SS patients [34-37]. Like CD4+ CD25- FoxP3+ isolated from SLE patients, FoxP3+ T cells isolated from SS patients are unable to suppress the immune response suggesting that in both diseases FoxP $3+\mathrm{T}$ cells are in fact demethylated and defective pre-Treg cells, an hypothesis that needs further confirmation [38]. Of note is the observation that the Treg/FoxP3 -/Scurfy mice develop a rapid salivary gland inflammation and impaired salivation function after oral application of lipopolysaccharide (LPS) confirming that functional Treg are important to prevent SS [39].

\subsection{SS and HERV Elements}

Throughout the genome, HERV are particularly sensitive to DNA methylation changes and several reports have identified such elements in salivary glands from SS patients [4041]. In an attempt to confirm the importance of HERV expression in salivary glands from SS, we have tested by RTPCR three HERV-E elements Fig. (1). Interestingly, all patients tested, except one, were positive for at least one HERV-E element. HERV are sequences derived from the integration of retroviral elements that account for at least $8 \%$ of the genome in comparison to only $3 \%$ of the genome being essential for life. Integration of most HERV into the genome occurred millions of years ago and, after mutations and deletions that render infection impossible, HERV are transmitted like other stable Mendelian elements. Analysis of the HERV mutation rate, $0.15-0.21 \%$ mutations per million years, between the 5' long terminal repeat (LTR) and 3' LTR, may be helpful for dating chromosomal integration [42]. HERV reactivation has been associated with exogenous viruses, mitogens, pro-inflammatory cytokines, steroid hormones, UVB irradiation, and X-ray exposure.

\section{A}

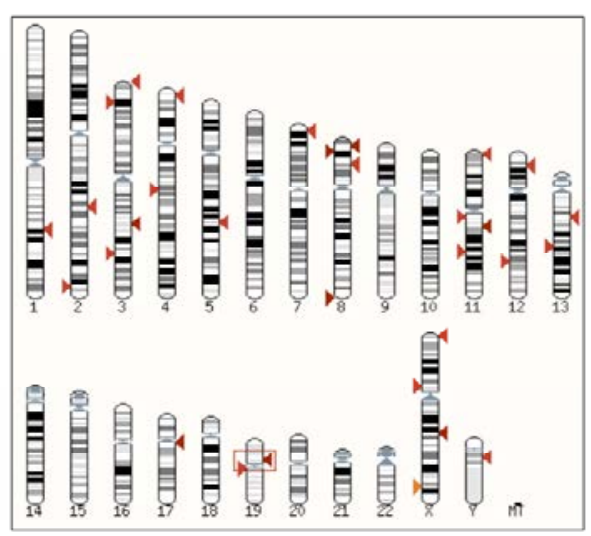

B

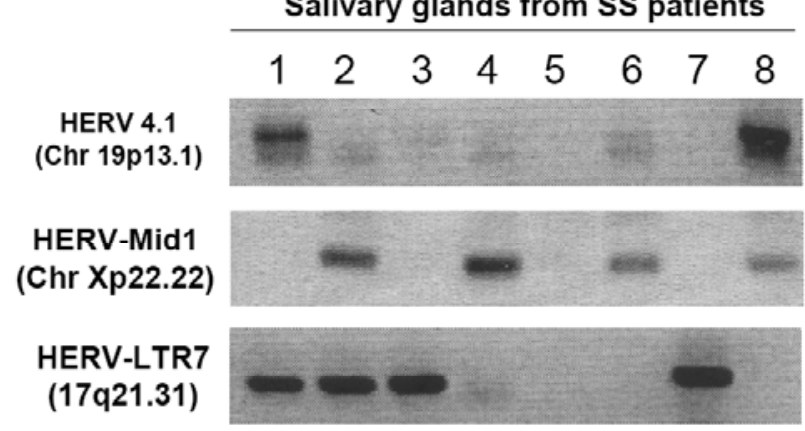

Fig. (1). Detection of human endogenous retrovirus transcripts in salivary glands from primary Sjögren's syndrome (SS) patients. AUsing the online basic local alignment search tool (BLAST) provided by ensemble (http://www.ensembl.org/Multi/ blastview), the HERV-E 4.1 sequence yielded several elements over the whole genome including a copy from $19 \mathrm{p} 13.1$ showing $100 \%$ identity to the 4.1 clone. B- Detection of HERV-E transcripts in salivary glands from SS patients by RT-PCR using HERV 4.1, HERV-Mid1 and HERV-LTR7 specific primers. Details have been described previously [42].

When overexpressed, HERV may interfere with the immune response by different mechanisms [43]. First, is the possibility of molecular mimicry between a retroviral protein and an autoantigen. For example, HRES-1 p30gag that crossreacts with the SLE autoantigen U1-snRNP is recognized as an autoantigen in up to $30 \%$ of SS patients and 50\% of SLE patients compared to less than $5 \%$ in a healthy control group [40]. Similarly, another unknown HERV, which may be Erv3 , cross-reacts with the p24 Gag of HIV-1 leading to the detection of anti-p24 Abs in the blood of patients with SS 
$(33 \%)$ and p24 related antigen in the salivary glands $(47 \%)$ in the absence of HIV and HTLV-1 infection [41]. Second, HERV gene products may possess immunomodulatory functions leading to repression or expansion of $\mathrm{T}$ cell populations as demonstrated in multiple sclerosis [44]. Third, HERV gene products may be homologous to a cellular protein and its over-expression modifies the cellular physiology [45]. Fourth, HERV may have integrated into or adjacent to immune-related genes and provide a new promoter that generates truncated proteins, or isoforms by alternative splicing. An example is the HERV-CD5 endogenous retrovirus, located $8 \mathrm{~kb}$ upstream CD5 gene, which generates an alternative transcript with CD5 [46-48]. Fifth, HERV can also influence neighbouring genes in an abnormal way. Presence of HERV-K(C4) in the $9^{\text {th }}$ intron of the $\mathrm{C} 4$ complement gene, which occurs in $70 \%$ of the population, resulted in a reduction of C4B protein [49]. Sixth, HERV integration may be considered as a genetic risk factor for AID, as reported for HERV-K113 and patients with SS and MS [50].

\subsection{SS and Lymphoma}

The methylation status of $\mathrm{CpG}$ islands of the proapoptotic death associated protein kinase (DAPK) was studied by Tosos et al. in samples from primary salivary gland lymphoma, the main SS associated lymphoma [51]. Surprisingly, the authors reported that demethylation of the DAPK gene characterized the SS sub-group when compared to the non-SS sub-group that are aberrantly hypermethylated. As a consequence, the tumor processes may be different between both sub-groups.

\section{CHROMOSOME X AND SS}

In humans, females inactivate one of their two $\mathrm{X}$ chromosomes in each cell in order to express X-linked genes at similar levels as males that have only one $\mathrm{X}$ chromosome since most $X$-linked genes are not sex-specific [52]. The active chromosome is referred to as $\mathrm{Xa}$, whereas the inactive one is referred to as $\mathrm{Xi}$. The choice of which $\mathrm{X}$ chromosome to inactivate, the maternally-derived or the paternallyderived, is a random choice made in somatic cells early in development. As a consequence, in newborn females we observe a mosaic of groups of cells with the maternallyderived $X$ inactivated next to groups of cells with the paternally-derived $\mathrm{X}$ inactivated. This pattern will be conserved throughout life since the daughter cells and all subsequent generations will keep the same parentally-derived X chromosome inactive as was chosen by its original ancestor cell.

$\mathrm{X}$ chromosome inactivation (XCI) originates on the long arm of the $X$ at position $\mathrm{Xq13.3}$ in an area of DNA referred to as the X-Inactivation Center (XIC) that contains the $35 \mathrm{~kb}$ human X-Inactivation Specific Transcript (XIST) gene that yields a long processed RNA transcript of approximately 19 $\mathrm{kb}$. The XIST RNA does not appear to code for protein and remains in the nucleus where it can repress the $\mathrm{Xi}$ by coating the contiguous chromosome and recruiting proteins that further establish an inactive heterochromatic state. Furthermore, stable Xi repression involves continuous activity of DNMT1, DNA methylation, a series of histone modifications (hypoacetylation, methylation, and ubiquitination), plus the accumulation of the repressor histone variant, macroH2A. All these modifications contribute to formation of the heterochromatic $\mathrm{Xi}$ structure, also referred to as the Barr body, which is generally located at the periphery of the nucleus. The Xa chromosome (i.e. euchromatin) assumes a more central location in the nucleus, similar to autosomes, and remains active.

Several arguments suggest a role for the X chromosome in the development of SS. The first, and indirect one, relates to the female predominance in SS with a sex ratio of $9: 1$ between females and males. The second one is related to the association between numerical abnormalities of the $\mathrm{X}$ chromosome and SS since several reports of SS women with trisomy $\mathrm{X}(47, \mathrm{XXX})$ or a super female phenotype (mosaic of

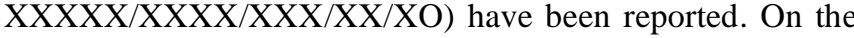
other hand, the skewed XCI, (i.e. a significant preferential inactivation of one parentally-derived $\mathrm{X}$ over the other) reported in scleroderma was not observed in SS [53]. The recent observation that increased demethylation of the $\mathrm{Xi}$ is associated with over-expression of the B-cell co-stimulator CD40-ligand in $\mathrm{CD}^{+} \mathrm{T}$ cells from women with SLE suggests that this should be tested in SS [54]. Cumulatively, the possible involvement of the $\mathrm{X}$ chromosome and related epigenetic defects in SS needs further investigation.

\section{RNA TRANSCRIPTS}

\section{1. miRNA}

MicroRNAs (miRNA) are genome-encoded 18- to 23base-pair (bp) RNAs that regulate gene expression at the post-transcriptional level. MiRNAs are transcribed in the nucleus by RNA polymerase II or III forming long preliminary transcripts which are cleaved by Drosha in the nucleus, exported to the cytoplasm by exportin 5, processed by Dicer into mature miRNA duplexes, and separated into single strands at the core of the multiprotein RNA-induced silencing complex (RISC) by argonaut proteins to generate miRNAs. It is generally accepted that miRNAs, by base pairing, bind the 3' untranslated region (UTR) of specific messenger RNAs (mRNA) for degradation or translational repression Fig. (2A). One third of the transcriptome is suspected to be regulated by the $800-1,000$ human miRNAs since one miRNA can alter the expression of hundreds of mRNAs. MiRNAs regulate different cellular processes such as embryonic development, cell differentiation, cell cycle, apoptosis, immune cell development, and immune responses. One of the characteristics of miRNAs is that they are highly resistant to degradation by RNases and can be isolated from biopsies and all types of body fluids including plasma, saliva, urine, and exosomes thus making miRNAs excellent biomarkers.

\section{2. miRNA in SS}

To date, few studies on miRNAs have been conducted in SS patients. According to Pauley et al., miR-146a and miR155 , two miRNAs up-regulated in response to the adaptative immune response in multiple cell types, are increased prior to disease onset in the salivary glands and in the peripheral blood mononuclear cells (PBMC) from both SS patients and from the SS prone mouse model C57B1/6.NOD-Aec1 Aec2 [55]. MiR-146a is a master gene regulator, activated by NFkappaB, that controls the TLR/IFN pathway through the 
TNF receptor-associated factor 6 (TRAF6), the IL-1 receptor associated kinase (IRAK1), the signal transducer and activator of transcription 1 (STAT1), and the interferon regulatory factor 5 (IRF5) [56]. Examination of miR-155 targets reveals an effect on the response of toll-like receptors and interleukin-1 receptors (TIRs) that are suspected to affect the immune response. Interestingly, the FoxP3 transcription factor, which is over-expressed in T cells infiltrating SS salivary glands (see above), has been shown to induce miR-155 expression. Another source of miR-155 may be salivary gland epithelial cells since we have observed that cultured salivary epithelial cells from SS express two fold more miR-155 than controls Fig. (2B). Two other miRNA, were also tested revealing that miR-181a but not miR-150 was overexpressed in cultured salivary glands from SS patients. MiR-181a participates in differentiation and proliferation by targeting, respectively, an homeobox protein (Hox-A11) and oncogenes (Tcl-1). Testing salivary gland biopsies from SS patients, Illei's group has observed that three miRNAs within the miR-17-92 cluster, miR-18a, hsa-miR-19a, and hsa-miR$19 \mathrm{~b}$, were upregulated [57]. The miR-17-92 cluster is crucial for $\mathrm{T}$ and $\mathrm{B}$ cell development and activation, and its overexpression is associated with a lymphoproliferative disease and an SLE-like disease with antinuclear Abs and glomerulonephritis. Two targets have been characterized for miR-1792, the pro-apoptotic protein Bim and the tumor suppressor (PTEN).

\section{3. miRNA in RA and SLE}

Similar to SS, the expression of miR-146a and miR-155 is increased in PBMC, and in fibroblast-like synoviocytes isolated from RA patients when compared to healthy controls
[58]. A correlation with RA disease activity was observed for miR-146a and miR-16. In contrast, miR-146a is underexpressed in PBMC from SLE patients and this underexpression negatively correlates with disease activity, thus providing an explanation for the link observed between interferon over-expression and miR-146a downregulation in SLE [11]. MiRNA analysis in SLE should not be restricted to miR-146a since the analysis of PBMC from SLE patients has revealed nine up-regulated miRNAs (miR-21, miR-61, miR78, miR-142-3p, miR-189, miR-198, miR-298, miR-299-pp, and miR-342) and seven down-regulated miRNAs (miR-175p, miR-112, miR-141, miR-184, miR-196a, miR-383, and miR-409-3p). In kidney biopsies from SLE patients, there are 66 miRNAs that are differentially expressed.

\section{POST-TRANSLATIONAL MODIFICATIONS}

A dysregulation of apoptosis is suspected to be involved in the early stage of SS and autoAb production. Supporting this possibility is the presence of histones, $52 \mathrm{kDa}$ and 60 $\mathrm{kDa} \mathrm{Ro} / \mathrm{SSA}, \mathrm{La} / \mathrm{SSB}$, and proteins relocated from the nucleus to apoptotic blebs on the cell surface of early apoptotic cells. Muller's group was the first to postulate that specific PTM histone modifications during cell death may generate neo-epitopes [13]. Indeed, apoptosis-associated acetylation of histones $\mathrm{H} 2 \mathrm{~B}$ and $\mathrm{H} 4$ provides important epitopes for pathogenic autoAbs in SLE, and administration of acetylated peptides in lupus prone mice accelerated the disease, while non-acetylated peptides are ineffective and phosphorylated peptides are protective. Similarly, apoptosis and PTM have been proposed to influence $60 \mathrm{kDa}$ Ro/SSA and La/SSB autoimmunity [59]. In fact, when using sera from SS patients, the Ab binding and the relative avidity is increased

A

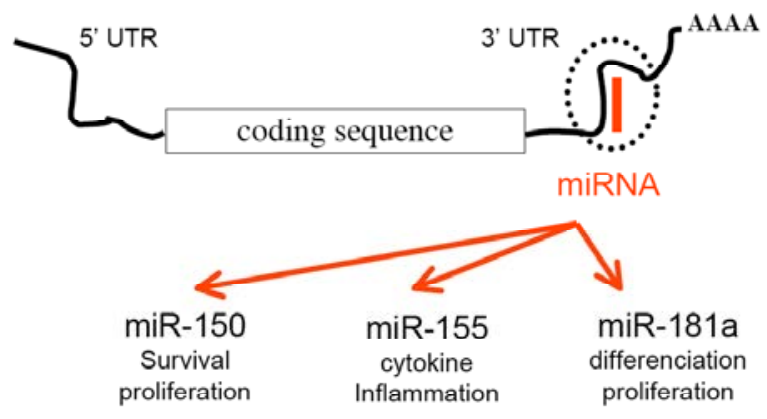

B

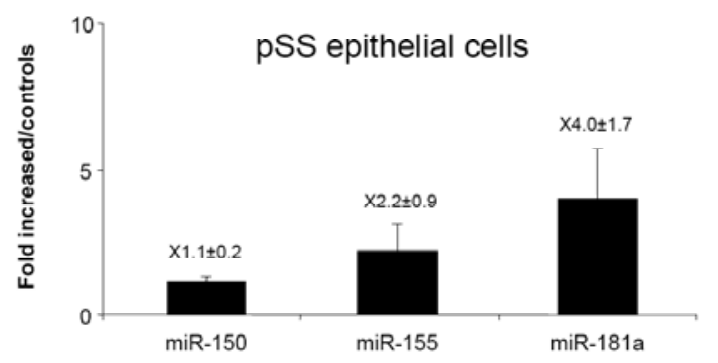

Fig. (2). MiRNA in epithelial cells isolated from primary Sjögren's syndrome (SS) salivary glands. A- A schematic diagram illustrating how miRNAs can potentially modulate mRNA degradation and translation through interactions with the 3' UTR. B- A quantitative PCR expression analysis of three miRNAs (miR-150, miR-155 and miR-181a) in epithelial cells cultured from six SS patients and six controls reveals that the expression levels of miR-155 and miR-181a were significantly higher in SS. Results, normalized to the house keeping miR-RNU48, are expressed relative to controls and there is no significant difference in the expression of miR-150. 
when La/SSB peptides phosphorylated at Serine 367 are used instead of crude peptides [60]. Modifications such as phosphorylation, citrullinisation or oxidation influence 60 kDa Ro/SSA peptide antigenicity, thus explaining why immunization with lipid oxidized $60 \mathrm{kDa}$ Ro/SSA peptides increases the antigenicity and favors epitope spreading to La/SSB, U1-snRNP and Sm [61-62]. The preferential recognition of the post-transcriptional forms of La/SSB by anti$\mathrm{La} / \mathrm{SSB}$ Abs in SS was confirmed when using parotid glands from patients [63]. Then, as demonstrated with citrullinisation in RA [64], it appears that apoptotic specific PTM could influence autoimmunity at different levels: initiation of autoimmunity, auto $\mathrm{Ab}$ production with epitope spreading, and production of pathogenic autoAb. Such a hypothesis warrants further investigation.

\section{CONCLUSION}

While our current knowledge is limited of how epigenetic modifications may influence the course of SS, epigenetic studies will undoubtedly help to understand SS features: age-related development, female predominance, geolocalization, cycles of flare and remission, association with lymphoma, and so forth. In addition, the reversible nature of epigenetic modifications offers the opportunity to identify target sites with potential impact on the prevention or progression of AID (Table 1). However, the revolution of epigenetics in AID and in SS [65] needs new collaborations between researchers from different research areas and the creation of the Brest Epigenetic task force during the Xth International Symposium on Sjögren's syndrome, 1-3 October 2009, Brest, France, will serve this purpose [66].

Table 1. Epigenetic Abnormalities Reported in Three Autoimmune Diseases: Sjögren's Syndrome (SS), Systemic Lupus Erythematosus (SLE), and Rheumatoid Arthritis (RA)

\begin{tabular}{|c|c|c|c|}
\hline & \multicolumn{3}{|c|}{ Autoimmune Diseases } \\
\hline & SS & SLE & RA \\
\hline \multicolumn{4}{|l|}{ DNA hypomethylation } \\
\hline $\mathrm{CD} 4+\mathrm{T}$ cells & Yes [22] & Yes [21] & Yes [15] \\
\hline Senescent CD4+ CD28- & No [29] & No [23] & Yes [23] \\
\hline Pre-Treg CD4+ CD25- Foxp3+ & (Yes ?) & Yes [24] & No \\
\hline $\mathrm{B}$ cells & $?$ & Yes [40] & $?$ \\
\hline \multicolumn{4}{|l|}{ miRNA } \\
\hline miR-146a & Upregulated [48] & Downregulated [51] & Upregulated [51] \\
\hline miR-155 & Upregulated [48] & Unaffected & Upregulated [51] \\
\hline miR-17-92 & Upregulated [50] & Unaffected & ? \\
\hline miR-181a & Upregulated [Fig 2] & Upregulated [59] & $?$ \\
\hline \multicolumn{4}{|l|}{$\mathrm{X}$ chromosome } \\
\hline Skewed XCI & No [46] & No [46] & Yes [46] \\
\hline CD40L expression on the inactive $\mathrm{X}$ & $?$ & Yes [47] & $?$ \\
\hline MECP2 polymorphism & $?$ & Yes [4] & No \\
\hline
\end{tabular}

\section{CONFLICT OF INTEREST}

None declared.

\section{ACKNOWLEDGEMENTS}

We are grateful to the "Association Française du Gougerot-Sjögren et des Syndromes Secs” for their support.

\section{REFERENCES}

[1] Mavragani, C.P.; Moutsopoulos, H.M. The geoepidemiology of Sjögren's syndrome. Autoimmun. Rev., 2010, 9(5), A305-310.

[2] Voulgarelis, M.; Dafni, U.G.; Isenberg, D.A.; Moutsopoulos, H.M. Malignant lymphoma in primary Sjögren's syndrome: a multicen- ter, retrospective, clinical study by the European Concerted Action on Sjögren's Syndrome. Arthritis. Rheum., 1999, 42(8), 1765-1772.

[3] Baimpa, E.; Dahabreh, I.J.; Voulgarelis, M.; Moutsopoulos, H.M Hematologic manifestations and predictors of lymphoma development in primary Sjögren syndrome: clinical and pathophysiologic aspects. Medicine. (Baltimore), 2009, 88(5), 284-293.

[4] Tobón, G.J.; Renaudineau, Y.; Hillion, S.; Cornec, D.; Devauchelle-Pensec, V.; Youinou, P.; Pers, J.O. The FMS-like tyrosine kinase3-ligand, a mediator for B cell survival is also a marker for lymphoma in primary Sjögren's syndrome. Arthritis. Rheum., 2010, 62(11), 3447-3456.

[5] Christodoulou, M.I.; Kapsogeorgou, E.K.; Moutsopoulos, H.M Characteristics of the minor salivary gland infiltrates in Sjögren's syndrome. J. Autoimmun., 2010, 34(4), 400-407.

[6] Salomonsson, S.; Jonsson, M.V.; Skarstein, K.; Brokstad, KA Hjelmström, P.; Wahren-Herlenius, M.; Jonsson, R. Cellular basis of ectopic germinal center formation and autoantibody production 
in the target organ of patients with Sjögren's syndrome. Arthritis. Rheum., 2003, 48(11), 3187-3201.

[7] Cobb, B.L.; Lessard, C.J.; Harley, J.B.; Moser, K.L. Genes and Sjögren's syndrome. Rheum. Dis. Clin. North Am., 2008, 34(4), 847-868.

[8] Mohammed, K.; Pope, J.; Le Riche, N.; Brintnell, W. ; Cairns, E., Coles, R.; Bell, D.A. Association of severe inflammatory polyarthritis in primary Sjögren's syndrome: clinical, serologic, and HLA analysis. J. Rheumatol., 2009, 36(9), 1937-1942.

[9] Delgado-Vega, A.M.; Alarcón-Riquelme, M.E.; Kozyrev, S.V. Genetic associations in type I interferon related pathways with autoimmunity. Arthritis. Res. Ther., 2010, 12, S2.

[10] Pers, J.O.; Tobón, G.J.; Jamin, C.; Renaudineau, Y.; Youinou, P. Conference Scene: Updating the highlights of Sjögren's Syndrome. Immunotherapy, 2010, 2(1), 13-20.

[11] Brooks, W.H.; Le Dantec, C.; Pers, J.O.; Youinou, P.; Renaudineau, Y. Epigenetics and autoimmunity. J. Autoimmun., 2010, 34(3), J207-219.

[12] Webb, R.; Wren, J.D.; Jeffries, M.; Kelly, J.A.; Kaufman, K.M.; Tang, Y.; Frank, M.B.; Merrill, J.; Kimberly, R.P.; Edberg, J.C.; Ramsey-Goldman, R.; Petri, M.; Reveille, J.D.; Alarcón, G.S.; Vilá, L.M.; Alarcón-Riquelme. M.E.; James, J.A.; Vyse, T.J.; Moser, K.L.; Gaffney, P.M.; Gilkeson, G.S.; Harley, J.B.; Sawalha, A.H. Variants within MECP2, a key transcription regulator, are associated with increased susceptibility to lupus and differential gene expression in patients with systemic lupus erythematosus. Arthritis Rheum., 2009, 60 (4), 1076-1084.

[13] Dieker, J.; Muller, S. Epigenetic Histone Code and Autoimmunity. Clin. Rev. Allergy. Immunol., 2010, 39(1), 78-84.

[14] Ballestar, E. Epigenetics Lessons from Twins: Prospects for Autoimmune Disease. Clin. Rev. Allergy Immunol., 2010, 39(1), 30-41.

[15] Fraga, M.F.; Ballestar, E.; Paz, M.F.; Ropero, S.; Setien, F.; Ballestar, M.L.; Heine-Suñer, D.; Cigudosa, J.C.; Urioste, M.; Benitez, J.; Boix-Chornet, M.; Sanchez-Aguilera, A.; Ling, C.; Carlsson, E.; Poulsen, P.; Vaag, A.; Stephan, Z.; Spector, T.D.; Wu, Y.Z.; Plass, C.; Esteller, M. Epigenetic differences arise during the lifetime of monozygotic twins. Proc. Natl. Acad. Sci. USA, 2005, 102(30), 10604-10609.

[16] Javierre, B.M.; Fernandez, A.F.; Richter, J.; Al-Shahrour, F.; Martin-Subero, J.I.; Rodriguez-Ubreva, J.; Berdasco, M.; Fraga, M.F.; O'Hanlon, T.P.; Rider, L.G.; Jacinto, F.V.; Lopez-Longo, F.J.; Dopazo, J.; Forn, M.; Peinado, M.A.; Carreño, L.; Sawalha, A.H.; Harley, J.B.; Siebert, R.; Esteller, M.; Miller, F.W.; Ballestar, E. Changes in the pattern of DNA methylation associate with twin discordance in systemic lupus erythematosus. Genome. Res., 2010, 20(2), 170-179.

[17] Grolleau-Julius, A.; Ray, D.; Yung, R.L. The Role of Epigenetics in Aging and Autoimmunity. Clin. Rev. Allergy Immunol., 2010, 39(1), 42-50.

[18] McCord, R.A.; Broccoli, D. Telomeric chromatin: roles in aging, cancer and hereditary disease. Mutat. Res., 2008, 647(1-2), 86-93.

[19] Finkel, T.; Deng, C.X.; Mostoslavsky, R. Recent progress in the biology and physiology of sirtuins. Nature, 2009, 460(7255), 587-591.

[20] Sequeira, J.; Boily, G.; Bazinet, S.; Saliba, S.; He, X.; Jardine, K.; Kennedy, C.; Staines, W.; Rousseaux, C.; Mueller, R.; McBurney, M. sirt1-null mice develop an autoimmune-like condition. Exp. Cell. Res., 2008, 314(16), 3069-3074.

[21] Grabiec, A.M.; Krausz, S.; de Jager, W.; Burakowski, T.; Groot, D.; Sanders. M.E.; Prakken, B.J.; Maslinski, W.; Eldering, E.; Tak, P.P.; Reedquist, K.A. Histone Deacetylase Inhibitors Suppress Inflammatory Activation of Rheumatoid Arthritis Patient Synovial Macrophages and Tissue. J. Immunol., 2010, 184(5), 2718-2728.

[22] Lee, J.H.; Song, M.Y.; Song, E.K.; Kim, E.K.; Moon, W.S.; Han, M.K.; Park, J.W.; Kwon, K.B.; Park, B.H. Overexpression of SIRT1 protects pancreatic beta-cells against cytokine toxicity by suppressing the nuclear factor-kappaB signaling pathway. Diabetes, 2009, 58(2), 344-351.

[23] Trenkmann, M.; Brock, M.; Ospelt, C.; Gay, S. Epigenetics in Rheumatoid Arthritis. Clin. Rev. Allergy Immunol., 2010, 39(1), 10-19.

[24] Darwaza, A.; Lamey, P.J.; Connell, J.M. Hydrallazine-induced Sjögren's syndrome. Int. J. Oral. Maxillofac. Surg., 1988, 17(2), 92-93.

[25] Taylor, J.A. Procainamide toxicity. Lancet, 1968, 1(7549), 978.

[26] Cannat, A.; Seligmann, M. Induction by isoniazid and hydrallazine of antinuclear factors in mice. Clin. Exp. Immunol., 1968, 3(1), 99-105.
Quddus, J.; Johnson, K.J.; Gavalchin, J.; Amento, E.P.; Chrisp, C.E.; Yung, R.L.; Richardson, B.C. Treating activated CD4+ T cells with either of two distinct DNA methyltransferase inhibitors, 5 -azacytidine or procainamide, is sufficient to cause a lupus-like disease in syngeneic mice. J. Clin. Invest., 1993, 92(1), 38-53.

[28] Mazari, L.; Ouarzane, M.; Zouali, M. Subversion of B lymphocyte tolerance by hydralazine, a potential mechanism for drug-induced lupus. Proc. Natl. Acad. Sci. USA, 2007, 104(15), 6317-6322.

[29] Lei, W.; Luo, Y.; Yan, K.; Zhao, S.; Li, Y.; Qiu, X.; Zhou, Y.; Long, H.; Zhao, M.; Liang, Y.; Su, Y.; Lu, Q. 1. Abnormal DNA methylation in CD4+ $\mathrm{T}$ cells from patients with systemic lupus erythematosus, systemic sclerosis, and dermatomyositis. Scand $J$. Rheumatol., 2009, 38(5), 369-374.

[30] Yin, H.; Zhao, M.; Wu, X.; Gao, F.; Luo, Y.; Ma, L.; Liu, S.; Zhang, G.; Chen, J.; Li, F.; Zuo, X.; Lu, Q. Hypomethylation and overexpression of CD70 (TNSF7) in CD4+ T cells of primary Sjögren's syndrome. J. Dermatol. Sci., 2010, 59(3), 198-203.

[31] Chen, Y.; Gorelik, G.J.; Strickland, F.M.; Richardson, B.C. Decreased ERK and JNK signaling contribute to gene overexpression in "senescent" CD4+CD28- T cells through epigenetic mechanisms. J. Leukoc. Biol., 2010, 87(1), 137-145.

[32] Lal, G.; Bromberg, J.S. Epigenetic mechanisms of regulation of Foxp3 expression. Blood, 2009, 114(18), 3727-3735.

[33] Garaud, S.; Le Dantec, C.; Berthou, C.; Lydyard, P.M.; Youinou, P.; Renaudineau, Y. Selection of the alternative exon 1 from the cd5 gene down-regulates membrane level of the protein in B lymphocytes. J. Immunol., 2008, 181(3), 2010-2018.

[34] Christodoulou, M.I.; Kapsogeorgou, E.K.; Moutsopoulos, N.M.; Moutsopoulos, H.M. Foxp3+ T-regulatory cells in Sjögren's syndrome: correlation with the grade of the autoimmune lesion and certain adverse prognostic factors. Am. J. Pathol., 2008, 173(5), 1389-1396.

[35] Sarigul, M.; Yazisiz, V.; Bassorgun, C,I.; Ulker, M.; Avci, A,B.; Erbasan, F.; Ulker, M.; Avci, A.B.; Erbasan, F.; Gelen, T.; Gorczynski, R.M.; Terzioglu, E. The numbers of Foxp3 + Treg cells are positively correlated with higher grade of infiltration at the salivary glands in primary Sjogren's syndrome. Lupus, 2010, 19(2), 138-145.

[36] Youinou, P.; Mackenzie, L.; Le Masson, G.; Papadopoulos, N.M.;Jouquan, J., Pennec, Y.L.; Angelidis, P.; Katsikis, P.; Moutsopoulos, H.M., Lydyard, P.M. CD5-expressing B lymphocytes in the blood and salivary glands of patients with primary Sjögren's syndrome. J. Autoimmun., 1988, 1(2), 185-194.

[37] Vaudo, G.; Bocci, E.B.; Shoenfeld, Y.; Schillaci, G.; Wu, R.; Del Papa, N.; Vitali, C.; Delle Monache, F.; Marchesi, S.; Mannarino, E.; Gerli, R. Precocious intima-media thickening in patients with primary Sjögren's syndrome. Arthritis. Rheum., 2005, 52(12), 3890-3897.

[38] Katsifis, G.E.; Moutsopoulos, N.M.; Wahl, S.M. T lymphocytes in Sjögren's syndrome: contributors to and regulators of pathophysiology. Clin. Rev. Allergy. Immunol., 2007, 32(3), 252-264.

[39] Sharma, R.; Deshmukh, U.S.; Zheng, L.; Fu, S.M.; Ju, S.T. X-linked Foxp3 (Scurfy) mutation dominantly inhibits submandibular gland development and inflammation respectively through adaptive and innate immune mechanisms. J. Immunol., 2009, 183(5), 3212-3218.

[40] Brookes, S.M.; Pandolfino, Y.A.; Mitchell, T.J.; Venables, P.J.; Shattles, W.G.; Clark, D.A.; Entwistle, A.; Maini, R.N. The immune response to and expression of cross-reactive retroviral gag sequences in autoimmune disease. Br. J. Rheumatol., 1992, 31(11), 735-742.

[41] Yamano, S.; Renard, J.N.; Mizuno, F.; Narita, Y.; Uchida, Y.; Higashiyama, H.; Sakurai, H.; Saito, I. Retrovirus in salivary glands from patients with Sjögren's syndrome. J. Clin. Pathol., 997, 50(3), 223-230.

[42] Renaudineau, Y.; Vallet, S.; Le Dantec, C.; Hillion, S.; Saraux, A.; Youinou, P. Characterization of the human CD5 endogenous retrovirus-E in B lymphocytes. Genes. Immun., 2005, 6(8), 663-671.

[43] Renaudineau, Y.; Garaud, S.; Le Dantec, C.; Alonso-Ramirez, R.; Daridon, C.; Youinou, P. Autoreactive B Cells and Epigenetics. Clin. Rev. Allergy Immunol., 2010, 39(1), 85-94.

[44] Perron, H.; Lang, A. The human endogenous retrovirus link between genes and environment in multiple sclerosis and in multifactorial diseases associating neuroinflammation. Clin. Rev. Allergy. Immunol., 2010, 39(1), 51-61.

[45] Fernandez, D.R.; Telarico, T.; Bonilla, E.; Li, Q., Banerjee, S., Middleton, F.A.; Phillips, P.E.; Crow, M.K.; Oess, S.; Muller- 
Esterl, W.; Perl, A. Activation of mammalian target of rapamycin controls the loss of TCRzeta in lupus $\mathrm{T}$ cells through HRES1/Rab4-regulated lysosomal degradation. J. Immunol., 2009, 182(4), 2063-2073.

[46] Renaudineau, Y.; Hillion, S.; Saraux, A.; Mageed, RA.; Youinou, $\mathrm{P}$. An alternative exon 1 of the CD5 gene regulates CD5 expression in human B lymphocytes. Blood, 2005, 106(8), 2781-2789.

[47] Garaud, S.; Le Dantec, C.; Jousse-Joulin, S.; Hanrotel-Saliou, C.; Saraux, A.; Mageed, R.A.; Youinou, P.; Renaudineau, Y. IL-6 modulates $\mathrm{CD} 5$ expression in B cells from patients with lupus by regulating DNA methylation. J. Immunol., 2009, 182(9), 5623-3562.

[48] Hippen, K.L.; Tze, L.E.; Behrens, T.W. CD5 maintains tolerance in anergic B cells. J. Exp. Med., 2000, 191(5), 883-890.

[49] Wouters, D.; van Schouwenburg, P.; van der Horst, A.; de Boer, M.; Schooneman, D.; Kuijpers, T.W.; Aarden, L.A.; Hamann, D. High-throughput analysis of the $\mathrm{C} 4$ polymorphism by a combination of MLPA and isotype-specific ELISA's. Mol. Immunol., 2009, 46(4), 592-600.

[50] Moyes, D.L.; Martin, A.; Sawcer, S.; Temperton, N.; Worthington, J.; Griffiths, D.J.; Venables, P.J. The distribution of the endogenous retroviruses HERV-K113 and HERV-K115 in health and disease. Genomics, 2005, 86(3), 337-341.

[51] Toso, A.; Aluffi, P.; Capello, D.; Conconi, A.; Gaidano, G.; Pia, F. Clinical and molecular features of mucosa-associated lymphoid tissue (MALT) lymphomas of salivary glands. Head Neck, 2009, 31(9), 1181-1187.

[52] Brooks, W.H. X Chromosome Inactivation and Autoimmunity. Clin. Rev. Allergy. Immunol., 2010, 39(1), 20-29.

[53] Ozcelik, T. X chromosome inactivation and female predisposition to autoimmunity. Clin. Rev. Allergy. Immunol., 2008, 34(3), 348-351.

[54] Lu, Q.; Wu, A.; Tesmer, L.; Ray, D.; Yousif, N.; Richardson, B. Demethylation of CD40LG on the inactive $\mathrm{X}$ in $\mathrm{T}$ cells from women with lupus. J. Immunol., 2007, 179(9), 6352-6358.

[55] Pauley, K.M.; Stewart, C.M.; Gauna, A.E.; Dupre, L.C.; Kuklani, R.; Chan, A.L.; Pauley, B.A.; Reeves, W.H.; Chan, E.K.; Cha, S. Altered miR-146a expression in Sjögren's syndrome and its functional role in innate immunity. Eur. J. Immunol., 2011, 41(7), 2029-2039.

[56] Tsitsiou, E.; Lindsay, M.A. microRNAs and the immune response. Curr. Opin. Pharmacol., 2009, 9(4), 514-520.

[57] Alevizos, I.; Illei, G.G. MicroRNAs in Sjogren's syndrome as a prototypic autoimmune disease. Autoimmun. Rev., 2010, 9(9), 618-621.
[58] Chan, E.K.; Satoh, M.; Pauley, K.M. Contrast in aberrant microRNA expression in systemic lupus erythematosus and rheumatoid arthritis: is microRNA-146 all we need? Arthritis Rheum., 2009, 60(4), 912-915.

[59] Reed, J.H.; Jackson, M.W.; Gordon, T.P. B cell apotopes of the 60 $\mathrm{kDa} \mathrm{Ro} / \mathrm{SSA}$ and $\mathrm{La} / \mathrm{SSB}$ autoantigens. J. Autoimmun., 2008 31(3), 263-267.

[60] Terzoglou, A.G.; Routsias, J.G.; Avrameas, S.; Moutsopoulos, H.M.; Tzioufas, A.G. Preferential recognition of the phosphorylated major linear B-cell epitope of La/SSB 349-368 aa by anti$\mathrm{La} / \mathrm{SSB}$ autoantibodies from patients with systemic autoimmune diseases. Clin. Exp. Immunol., 2006, 144(3), 432-439.

[61] Terzoglou, A.G.; Routsias, J.G.; Moutsopoulos, H.M.; Tzioufas, A.G. Post-translational modifications of the major linear epitope 169-190aa of Ro60 kDa autoantigen alter the autoantibody binding. Clin. Exp. Immunol., 2006, 146(1), 60-65.

[62] Scofield, R.H.; Kurien, B.T.; Ganick, S.; McClain, M.T.; Pye, Q.; James, J.A.; Schneider, R.I.; Broyles, R.H.; Bachmann, M.; Hensley, K. Modification of lupus-associated $60-\mathrm{kDa}$ Ro protein with the lipid oxidation product 4-hydroxy-2-nonenal increases antigenicity and facilitates epitope spreading. Free Radic. Biol. Med., 2005, 38(6), 719-728

[63] Stea, E.A.; Routsias, J.G.; Samiotaki, M.; Panayotou, G.; Papalambros, E.; Moutsopoulos, H.M.; Tzioufas, A.G. Analysis of parotid glands of primary Sjögren's syndrome patients using proteomic technology reveals altered autoantigen composition and novel antigenic targets. Clin. Exp. Immunol., 2007, 147(1), 81-89.

[64] Klareskog, L.; Rönnelid, J.; Lundberg, K.; Padyukov, L.; Alfredsson, L. Immunity to citrullinated proteins in rheumatoid arthritis. Annu. Rev. Immunol., 2008, 26, 651-675.

[65] Renaudineau, Y. The Revolution of Epigenetics in the Field of Autoimmunity. Clin. Rev. Allergy Immunol., 2010, 39, 1-2.

[66] Lu, Q.; Renaudineau, Y.; Cha, S.; Ilei, G.; Brooks, W.H.; Selmi, C.; Tzioufas, A.; Pers, J.O.; Bombardieri, S.; Gershwin, M.E.; Gay, S.; Youinou, P. Epigenetics in autoimmune disorders: Highlights of the 10th Sjögren's Syndrome Symposium. Autoimmun. Rev., 2010, 9(9), 627-630.

[67] Vinuesa, C.G.; Rigby, R.J.; Yu, D. Logic and extent of miRNAmediated control of autoimmune gene expression. Int. Rev. Immunol., 2009, 28(3-4), 112-138. 